Parenting

\section{Parenting programmes}

\section{N Spencer}

\section{What is the likely impact on child mental health?}

$\mathrm{T}$ he December edition of the Archives carried two complementary papers $^{12}$ on need and demand for, and impact of, parenting programmes, reflecting increasing professional and political interest in interventions to improve parenting. This interest is fuelled by the apparent increase in the prevalence of child mental health problems and greater awareness of the long term impact of childhood conduct disorders. ${ }^{3}$ Interest in and enthusiasm for parenting programmes, however, should not divert from the critical question-what is the likely impact of parenting programmes on the mental health of the child population in this and other similar countries?

\section{THE PARENTING AND CHILD MENTAL HEALTH CONTINUUM}

Parenting and child mental health problems are not "all or nothing" phenomena. They represent a continuum along which arbitrary cut off points are used to define "normality" and "abnormality". This fundamental characteristic, shared with many other socially and culturally related child health problems, helps to explain the difficulties of defining "good enough" parenting ${ }^{4}$ and the point at which childhood behaviour becomes abnormal. Although often treated as characteristics of individual families or children, they are embedded in societies and cultures and are powerfully influenced by social, economic, and political contexts. ${ }^{4}$ Recent work on the 1958 British births cohort $^{5}$ confirms previous work showing close links between educational attainment and psychosocial adjustment in late adolescence and early adulthood, ${ }^{6}$ showing that family social class exerts its effects on both educational attainment and psychosocial adjustment through material deprivation, parental aspirations, and involvement, as well as school composition.

Rose $^{7}$ argues that the distribution of risk exposures across a population determines the extent of problems at the lower tail of the distribution. High population levels of alcohol consumption are associated with high levels of alcohol related diseases; high population levels of salt consumption are associated with high levels of hypertension. Similarly, high population levels of material deprivation, low parental educational attainment, and family violence are likely to result in high levels of parenting and child and adolescent mental health problems.

Even if, as Patterson and colleagues ${ }^{12}$ have shown, parental education is acceptable to parents and the programmes are effective in improving conduct disorders, the above characteristics of parenting and child mental health are likely to limit the impact of parent education programmes on child mental health across the whole population. Patterson and colleagues $^{1}$ acknowledge that parenting programmes are not an alternative to changes in social policy to make the job of parenting easier and reduce the population level of risk exposures. However, there remains a danger that their results, and those of others, ${ }^{8}$ will be used by politicians intent on a "quick fix" to promote parenting education as an alternative to social change.

\section{PARTICIPATION, DROP OUT, AND GENERALISABILITY}

There are additional warning signs in these two papers, and in the wider evidence base used to show the effectiveness of parenting programmes, ${ }^{89}$ that caution against a major public health initiative based on these programmes, at least until a more robust evidence base is established. Only $14 \%$ of the 800 parents ( $10 \%$ of all 1155 approached) responding to the postal questionnaire expressed a definite interest in attending a parenting group. ${ }^{1}$ When parents were invited to participate in the randomised controlled trial (RCT), ${ }^{2}$ only $30 \%$ agreed, despite the fact that their children were above the mean score on the Eyberg Intensity Scale. These results suggest that both interest and participation in parenting programmes is likely to reach only a minority of families with children. The authors argue, with some justification ${ }^{2}$ that an uptake of $30 \%$ "represented a significant level of interest in the intervention". However, the question remains: would these levels of participation be sufficient to make a real impact on child mental health across the whole population?

Among those agreeing to participate in the RCT and randomised to the intervention group, only $57 \%$ attended $50 \%$ or more of the sessions, raising further questions about the potential impact if these programmes were universally available.
The social patterning of participation also raises a question over the likely impact on population rates of child mental health problems. Not only were the parents responding to the initial questionnaire more likely to come from higher social groups, ${ }^{1}$ but $11.4 \%$ of participants in the RCT were in social classes IV and V compared with $14.9 \%$ of non-participants. The social class of those attending less than $50 \%$ of the sessions is not stated, but it is reasonable to assume that the reasons given by the authors for dropping out of the programme ${ }^{2}$ would be more prevalent among lower social groups.

The study reported in these papers was conducted in a relatively affluent population and it is not clear whether the results are generalisable across the country, especially in severely deprived areas where the problems of parenting and child mental health are most prevalent. The authors argue, appropriately in my view, for a universal rather than a targeted service, but very low participation rates in socially deprived areas would further undermine the likely impact on child mental health.

The RCT shows significant differences between intervention and control groups in mean conduct problem scores at both immediate and six month follow up, and mean Eyberg Intensity scores at six months. There was a significant positive short term effect of the intervention on parental social dysfunction. There were no significant effects on other child or parental domains and the effect sizes on conduct problems, though not reported in the conventional way, are likely to be small judging by the $\mathrm{p}$ values (0.041 immediately; 0.034 at six months). These effects should not be dismissed, but further studies in different areas of the country will be advisable before assuming that these results are generalisable. Current evidence of effectiveness of parenting programmes comes from North America and is based on interventions with parents at high risk. ${ }^{8}$

\section{MORE EVIDENCE OF LIKELY IMPACT NEEDED}

In summary, these papers ${ }^{12}$ are a valuable contribution to the literature on the impact of parenting programmes. However, they raise as many questions as answers. Given the continuum of parenting and child mental health and their sensitivity to societal level influences, parenting programmes alone cannot be expected to have a major impact on child mental health. Whether the problems of low participation, high drop out, and differential social uptake can be overcome, in order to enable universal parenting programmes to contribute effectively to public health, will have to await further evidence.

Arch Dis Child 2003;88:99-100 


\section{Author's affiliation \\ N Spencer, University of Warwick, Coventry, UK}

Correspondence to: Professor N Spencer University of Warwick, Coventry CV4 7AL, UK; n.j.spencer@warwick.ac.uk

\section{REFERENCES}

1 Patterson J, Mockford C, Barlow J, et al. Need and demand for parenting programmes in general practice. Arch Dis Child 2002;87:468-71.
2 Patterson J, Barlow J, Mockford C, et al. Improving mental health through parenting programmes: block randomised controlled trial. Arch Dis Child 2002;87:427-7.

3 Scott S. Aggressive behaviour in childhood. BM 1998;316:202-6.

4 Taylor J, Spencer NJ, Baldwin N. The social, economic and political context of parenting. Arch Dis Child 2000;82:113-20.

5 Sacker A, Schoon I, Bartley M. Social inequality in educational achievement and psychosocial adjustment throughout childhood: magnitude and mechanisms. Soc Sci Med 2002;55:863-80. Sci Med 2002;55:863-80.

6 Power C, Hertzman C. Health, well-being, and coping skills. In: Keating D, Hertzman C, eds. Developmental health and the wealth of nations. New York and London: Guilford Press, 1999:41-54.

7 Rose G. The strategy of preventive medicine. Oxford: Oxford Medical Publications, 1992.

8 Barlow J, Stewart-Brown S. Behaviour problems and group based parenting education programmes. Developmental and Behavioral Pediatrics 2000;21:356-70.

9 Scott S, Spender Q, Doolan M, et al. Multicentre controlled trial of parenting groups for antisocial behaviour in clinical practice. BM 2001;323: 194-7.

\section{POSTCARD FROM DOWN UNDER}

\section{The fat of the land}

T

hey say that you are what you eat. By current trends it's looking like, by the year 2050 , we'll all be $150 \mathrm{~kg}$ by our thirtieth birthday and the only exercise we'll get is activating the direct computer access to McKFC for our next order of a pork fat thick shake.

Obesity is no laughing matter for those living with it, particularly for children. The jolly image of the subtly named Fatty from Enid Blyton's Famous Five rarely corresponds with the miserable, unfit, teased child that you and I meet in clinic. And we're living in the middle of an epidemic of it, or so we're told. Our children are getting fatter, doing less exercise and eating worse and worse foods. On the other hand, the other epidemic we're living with is the one of obsessive thinness, of which the worst extreme is anorexia nervosa and associated illnesses. It is very confusing to try and figure out why society has these two apparently paradoxical morbidities.

But then again, perhaps it isn't so paradoxical. We live in a society obsessed by weight and appearance. After all, what is the second question, after gender, asked by every parent of a newborn baby? The weight of course-a number almost as irrelevant in the vas majority of cases as the Apgar score (itself now the third question asked by many parents). We weigh and plot and encourage and scold throughout childhood. And then we wonder why most ten year old girls have been on a diet and why those of us who store energy more efficiently than others decide to opt out and close their ears to everything further that health professionals have to say on the subject.
What can we do? It has taken decades of persistence to get our profession to take the issue of surveillance of weight and growth seriously, and it would be disastrous to go back to a situation where nobody cared. But it does seem odd that we bemoan a society obsessed by weight at the same time as fuelling that obsession, and being aghast each time we meet an overweight person who has effectively opted out.

Perhaps we need to look more closely at why people opt out. Australia might offer some clues. Australia has the second highest levels of childhood obesity in the world, but at the same time is one of the most active sporting nations in the world. For example, in successive Olympic games Australians have won more gold medals per head of population than any other country. So, where do all the overweight folk come from? Are they simply sitting at home watching it on TV? Well, yes they are, for the most part. There is no place in highly competitive sport for someone who is less than excellent. It takes great strength of character to keep on trying if everyone else is better than you, is beating you, and adverts on TV remind you-as in a recent Australian banking advertising campaign - that "No one remembers who came second."

Another lesser factor must be the sponsorship. The fast food giants effectively run the Australian school football code leagues, with voucher prizes for winners and runners-up. Non-prize winners would tag along for commiseration fatty meals. It wouldn't take long for the message "Feeling low? Eat something!" to establish itself in a young mind. It is worth remembering that a fast-food chain has never yet done something for entirely altruistic reasons, no matter how much they might protest that they do.

We need to maintain our vigilance, our disapproval if you like, regarding serious obesity. At the same time, we need to insist that taking part-getting out there and having some fun and some exercise-is every bit as important as winning. This may sound like wishywashy leftie thinking, but it is vitally impor tant for our future health. If winning is the only thing, then what incentive is there to go on if you can't win? It took me years to understand why I liked to cycle so much (one of the major reasons is that I'm never going to lose-or for that matter win-anything). I don't need to anxiously await selection onto a team, or fear letting down team members with an appalling own goal. I'm a wimp, I know, but for many of us, this is our memory of sport.

In a tennis tournament involving 100 players, 99 must lose. In a soccer match, unless there is a draw, 11 players lose. Often the draw is seen as all 22 people losing. For those of us who are more jaded and cynical this might be a metaphor for life, but we shouldn't burden our children with it early in life. There must be a way where there can be more winners, or where we can be less obsessed by winning, and by weight, and a little more inclusive. The alternative is that we all lose, and that we all become the fat of the land.

I D Wacogne Dr Wacogne was on secondment at the Royal Children's Hospital, Brisbane for two years and is now a locum consultant in general paediatrics at Birmingham Children's Hospital, UK. 